\title{
PENGARUH STRESSOR TERHADAP PRESTASI KERJA MELALUI STRESS KERJA KARYAWAN PTPN XII KEBUN NGRANGKAH PAWON KEDIRI
}

\author{
Diah Kusumawati \\ Program Studi Manajemn FEB UMM \\ E-mail:diahkusuma@yahoo.co.id
}

\begin{abstract}
The purpose of this study were (1) to determine the stressors, (2) to know the job stress level (3) to find out the level of work performance and (4) whether the stressor effect on the employee stress at PTPN XII Kebun Ngrangkah Pawon Kediri. Analysis tool used to determine the stressors and stress that and to determine the level of employee performance was range-scale analysis. To know the effect of stressor on the job stress and its impact on employee performance was used path analysis model. The results of the analysis indicate that stressor and stress were in high level category. The level of employee performance was also in high category. The results of path analysis show that was a significant effect between a stressor to employee's job stress, there was also a significant effect between the job-stress to employees' performance. It mean that there was a significant effect between stressors to performance level through job stress. Based on the results, it could be suggested that the level of work stressors and job stress should be reduced. Giving reward would be better applied for better working employees, so it could motivate employees enthusiastic in their work.
\end{abstract}

Keywords: Stressor, Job Stress and Job Performance

\section{PENDAHULUAN}

Karyawan bagian pemetik kopi dalam pelaksanaan kegiatan operasional perusahaan, menjadi kunci utama bagi keberhasilan yang dapat dicapai selama ini. PTPN XII (Persero: Kebun Ngrangkah Pawon Kediri merupakan perusahaan yang bekerja dalam bidang perkebunan. Pekerjaan bagian pemetik meliputi pemetik yang berjumlah 400 karyawan dan bertugas melakukan pemetikan buah kopi. Setiap karyawan diharuskan menghasilkan kurang lebih 40kg kopi per hari. Adanya tuntutan dari karyawan lain juga menjadi penyebab utama terjadinya stress.

Contoh konflik yang terjadi antar karyawan yaitu perbedaan pendapat atau ketidakcocokan dalam diri individu. Aturan dan pengaturan yang diterapkan perusahaan dirasa juga berlebihan, di- mana pembagian wilayah panen tidak sepadan dengan jumlah karyawan yang ditugaskan. Atasan selalu menuntut agar karyawan bekerja sesuia dengan bagian yang sudah ditentukan. Gaya manajerial dari atasan dalam pengambilan keputusan hanya secara sepihak tanpa melihat latar belakang permasalahan. Sebagai contoh disini yaitu pimpinan melakukan pemberhentian kerja tanpa melihat kinerja yang selama ini dihasilkan.

Kondisi tersebut apabila tidak diikuti dengan ketenangan sikap dan kestabilan emosi maka secara langsung para karyawan akan merasakan beban psikologis semakin berlebihan yang pada akhirnya stress kerja semakin meningkat. Apabila kondisi tersebut dapat dikendalikan secara maksimal maka secara langsung juga akan mempengaruhi terhadap prestasi kerja yang akan dicapai 
oleh karyawan. Perusahaan mengalami penurunan prestasi kerja karena adanya deviasi. Deviasi timbul karena terjadinya ketidaktenangan dan perasaan cepat bosan para karyawan dalam bekerja diperusahaan, sikap karyawan yang cenderung bekerja sesuai dengan keinginan masing-masing. Berdasarkan uraian dari latar belakang diatas, maka peneliti mengangkat judul tentang Pengaruh Stressor Terhadap Prestasi Kerja Melalui Stress Kerja Karyawan Pada PTPN XII (Persero) Kebun Ngrangkah Pawon Kediri.

Sehinggapenelitian ini memiliki rumusan masalah sebagai berikut: (a) Bagaimana stressor pada PTPN XII (Persero) Kebun Ngrangkah Pawon Kediri. (b) Bagaimana stress kerja pada PTPN XII (Persero) Kebun Ngrangkah Pawon Kediri. (c) Bagaimana prestasi kerja pada PTPN XII (Persero) Kebun Ngrangkah Pawon Kediri. (d) Apakah ada pengaruh yang signifikan antara stressor dengan stress kerja pada PTPN XII (Persero) Kebun Ngrangkah Pawon Kediri. (e)Apakah ada pengaruh yang signifikan antara stress kerja dengan prestasi kerja pada PTPN XII (Persero) Kebun Ngrangkah Pawon Kediri. (f) Apakah ada pengaruh yang signifikan antara stressor dengan prestasi kerja yang melalui stress kerja pada PTPN XII (Persero) Kebun Ngrangkah Pawon Kediri.

Dalam hal ini peneliti membatasi masalah hanya pada stressor karyawan bagian pemetik kopi berkaitan dengan tuntutan tugas, tuntutan peran, tuntutan antar pribadi, struktur organisasi, kepemimpinan organisasi dan tahap hidup organisasi terhadap variabel stress kerja dan prestasi kerja pada PTPN XII (Persero) Kebun Ngrangkah Pawon Afdeling Badek Kediri.

Peneliti memiliki beberapa tujuan dalam penelitian ini, antara lain sebagai berikut: (a) Untuk mendiskripsikan stressor pada PTPN XII (Persero) Kebun Ngrangkah Pawon Kediri. (b) Untuk mendiskripsikan stress kerja pada PTPN XII (Persero) Kebun Ngrangkah Pawon Kediri. (c) Untuk mendiskripsikan prestasi kerja karyawan pada PTPN XII (Persero) Kebun Ngrangkah Pawon Kediri. (d) Untuk mengetahui apakah ada pengaruh yang signifikan antara stressor dengan stess kerja pada PTPN XII (Persero) Kebun Ngrangkah Pawon
Kediri. (e) Untuk mengetahui apakah ada pengaruh yang signifikan antara stress kerja dengan prestasi kerja karyawan pada PTPN XII (Persero) Kebun Ngrangkah Pawon Kediri. (f) Untuk mengetahui apakah ada pengaruh yang signifikan antara stressor dengan prestasi kerja yang melalui stress kerja karyawan pada PTPN XII (Persero) Kebun Ngrangkah Pawon Kediri.

Sehingga diharapkan penelitian ini memiliki manfaat sebagai berikut: (a) Untuk masukan bagi perusahaan agar lebih memperhatikan kondisi karyawan dan dalam pengambilan keputusan dibidang personalia, khususnya mengenai pengaruh stress terhadap prestasi kerja karyawan. (b) Sebagai dasar dan acuan penelitian selanjutnya yang mengkaji masalah stressor, stress kerja dan prestasi kerja di tempat kerja.

\section{TINJAUAN PUSTAKA}

Rivanto (2009) melakukan penelitian dengan judul Pengaruh Stressor Terhadap Stress Kerja Dan Kinerja Karyawan Pada Perusahaan Susu Sapi Anugerah Kediri. Alat analisis yang digunakan adalah regresi linier berganda uji t dengan hasil penelitian menunjukkan adanya pengaruh yang signifikan antara stressor terhadap stress kerja dan pengaruh yang signifikan antara stress kerja dengan prestasi kerja.Stressor adalah keadaan lingkungan khusus sebagai sumber potensial stress (Gibson, 1996). Dengan demikian dapat disimpulkan bahwa stressor merupakan sumber potensial atau penyebab terjadinya stress pada diri seorang karyawan.

Faktor organisasi penyebab stress yaitu: (a) Tuntutan tugas merupakan faktor yang terkait dengan tuntutan atau tekanan untuk menunaikan tugasnya secara baik dan benar. (b) Tuntutan peran berhubungan dengan tekanan yang diberikan pada seseorang sebagai fungsi dari peran tertentu yang dimainkan dalam organisasi itu. (c) Tuntutan antar pribadi adalah tekanan yang diciptakan oleh karyawan lain. (d) Struktur Organisasi menentukan tingkat diferensiasi dalam organisasi, tingkat aturan dan peraturan dan dimana keputusan itu diambil. (e) Kepemimpinan organisasi adalah menggambarkan gaya manajerial dari atasan. 
Stress kerja adalah suatu tanggapan penyesuaian diperantarai oleh perbedaan - perbedaan individu dan atau proses psikologis yang merupakan suatu konsekuensi dari setiap tindakan dari luar(lingkungan), situasi, atau peristiwa yang menetapkan permintaan psikologis dan atau fisik berlebihan kepada seseorang (Gibson 1996). Konsekuensi dari stress kerja yaitu:(a) Physiological (Fisiologis), yaitu stress yang dapat menciptakan perubahan dalam metabolisme, meningkatkan laju detak jantung dan pernafasan, meningkatkan tekanan darah, menimbulkan sakit kepala dan menyebabkan serangan jantung. (b) Psychological (Psikologis), yaitu stress yang dapat menyebabkan ketidakpuasan dalam bekerja. (c) Behavior (Perilaku), yaitu stress yang berpengaruh terhadap perubahan produktifitas, absensi juga perubahan dalam kebiasaan makan, meningkatnya merokok dan konsumsi alkohol, bicara cepat, gelisah dan gangguan tidur.

Prestasi kerja adalah hasil kerja secara kualitas dan kuantitas yang dicapai oleh seorang karyawan dalam melaksanakan tugasnya sesuai dengan tanggung jawab yang diberikan kepadanya (Mangkunegara, 2000). Indikator prestasi kerja yaitu: (a) Kualitas kerja yang merupakan mutu produk yang dihasilkan sesuai dengan standart yang ditetapkan. (b) Kuantitas kerja yang merupakan jumlah produk yang dihasilkan oleh para karyawan. (c) Ketepatan waktu yang merupakan waktu yang digunakan dalam menyelesaikan pekerjaan sesuai dengan target yang telah ditentukan.

Berdasarkan penelitian terdahulu, landasan teori, tujuan penelitian dan keadaan di lapangan maka dapat diambil hipotesis sebagai berikut: (a) Ada pengaruh yang signifikan antara stressor terhadap stress kerja karyawan pada PTPN XII (Persero) Kebun Ngrangkah Pawon Kediri. (b) Ada pengaruh yang signifikan antara stress kerja terhadap prestasi kerja karyawan pada PTPN XII (Persero) Kebun Ngrangkah Pawon Kediri.

\section{METODE PENELITIAN}

Jenis penelitian yang dilakukan adalah penelitian survey, dimana peneliti melakukan observasi dalam pengumpulan data, peneliti hanya mencatat data seperti apa adanya menganalisis, dan menafsirkan data tersebut. Penelitian ini menggunakan data primer berupa kuisioner yang merupakan instrument untuk mengetahui bagaimana segala sesuatu dari obyek yang diteliti. Kuisioner disebarkan untuk memperoleh data berupa jawaban-jawaban responden yang kemudian dijadikan informasi sebagai bahan dasar pengambilan kesimpulan. Data sekunder adalah data primer yang telah diolah lebih lanjut dan disajikan oleh pihak pengumpul data primer atau oleh pihak lain Umar (2003). Adapun data sekunder dalam penelitian ini adalah berupa gambaran umum perusahaan, tenaga kerja dan bahan lain yang menunjang penelitian ini.

Penelitian ini populasi yang digunakan adalah jumlah karyawan PTPN XII (Persero) Kebun Ngrangkah Pawon Kediri yaitu sebanyak 400 karyawan. Sedangkan sampel yang digunakan adalah $10 \%$ dari jumlah populasi yaitu 400 orang menjadi 40 orang. Teknik Pengambilan Sampel dalam penelitian ini adalah menggunakan metode simple random sampling, yaitu pengambilan sampel yang dilakukan secara acak dengan menggunakan tabel bilangan acak atau dengan pengundian dimana sampelnya homogen. seluruh karyawan bagian pemetik kopi pada PTPN XII (Persero) Kebun Ngrangkah Pawon Kediri.

Teknik pengumpulan data yang digunakan oleh peneliti yaitu: (a) Wawancara, di mana peneliti melakukan wawancara langsung dengan beberapa karyawan maupun pimpinan dalam rangka memperoleh data atau mendapatkan informasi. (b) Kuesioner, di mana peneliti memberikan/menyebarkan pernyataan yang secara logis berhubungan dengan masalah penelitian dan tiap pertanyaan merupakan jawaban-jawaban yang mempunyai makna dalam menguji hipotesa.

Definisi Operasional Variabel dalam penelitian ini terdiri dari variabel exogenous yang merupakan konsep persepsi terhadap variabel stressor (X) yaitu suatu kondisi yang cenderung menyebabkan stress. Indikator dari variabel stressor ini adalah Tuntutan tugas, Tuntutan peran, Tuntutan antar pribadi, Struktur organisasi, dan Kepemimpinan 
organisasi. Variabel Intervening dalam penelitian ini adalah stress kerja $(Y)$. indikator dalam variabel ini adalah Stress fisiologis, Stress psikologis, Stress perilaku. Sedangkan variabel Endogenous dalam penelitian ini adalah prestasi kerja $(Z)$. indikator dalam variabel ini adalah Kuantitas Pekerjaan, Kualitas Pekerjaan, dan Ketepatan Waktu.

Metode Pengukuran Variabel dalam penelitian ini menggunakan teknik skala likert. Dalam penelitian ini mengunakan 4 kategori, dan tidak menggunakan 5 kategori, karena menurut Nazir (2003) skala Likert menggunakan item yang secara pasti baik dan secara pasti buruk, tidak dimasukkan yang agak baik, yang kurang buruk, dan yang netral.

Teknik Pengujian Instrumen yang digunakan dalam penelitian ini adalah uji validitas dan uji reabilitas. Uji validitas adalah ukuran yang menunjukkan tingkat-tingkat kevalidan suatu instrument menurut Arikunto (1995) dalam Riduwan (2008). Suatu instrumen dikatakan valid jika mempunyai validitas tinggi dan mampu mengukur variabel yang diteliti secara tepat. Tinggi rendahnya validitas instrument menunjukkan sejauh mana data yang ter- kumpul tidak menyimpang gambaran tentang validitas yang dimaksud.

Uji Reliabilitas menurut Arikunto (2002) menunjukkan pada suatu pengertian bahwa suatu instrumen dapat dipercaya untuk dapat digunakan sebagai alat pengumpul data karena instrumen tersebut sudah baik, dengan demikian reliabilitas menunjuk pada tingkat keterhandalan sesuatu. Uji ini diperlukan untuk mengetahui kestabilan alat ukur. Sebuah alat ukur dikatakan reliabel, andaikan pengulangan pengukuran untuk subyek penelitian yang sama menunjukkan hasil yang konsisten. Rumus yang digunakan untuk mencari reliabilitas dalam penelitian ini adalah dengan menggunakan rumus Alpha Cronbach (Riduwan, 2008), karena instrumen yang digunakan memiliki rentang nilai. Teknik analisis Data yang digunakan dalam penelitian ini adalah rentang skala dan analisis jalur (path analisys). Rentang skala adalah alat yang digunakan untuk mengukur dan menilai variabel yang diteliti. Dalam penelitian ini analisis rentang skala digunakan untuk mengetahui tingkat stressor, stress kerja, dan prestasi kerja karyawan pada PTPN XII (Persero) Kebun Ngrangkah Pawon Kediri

Tabel 1. Rentang Skala Penilaian Stressor Kerja, Stress Kerja Dan Prestasi Kerja

\begin{tabular}{clll}
\hline Nilai Rentang Skala & \multicolumn{1}{c}{ Stressor Kerja } & \multicolumn{1}{c}{$\begin{array}{c}\text { Penilaian } \\
\text { Stress Kerja }\end{array}$} & \multicolumn{1}{c}{ Prestasi Kerja } \\
\hline $40-69$ & Sangat rendah & Sangat rendah & Sangat rendah \\
$70-99$ & Rendah & Rendah & Rendah \\
$100-129$ & Tinggi & Tinggi & Tinggi \\
$130-160$ & Sangat tinggi & Sangat tinggi & Sangat tinggi \\
\hline
\end{tabular}

Sumber: Data diolah

Analisis Jalur (Path Analysis), teknik analisis jalur ini akan digunakan dalam menguji besarnya sumbangan (kontribusi) yang ditunjukkan oleh koefisien jalur pada setiap diagram jalur dari hubungan kausal antar variabel X terhadap Z secara langsung dan secara tidak langsung terhadap Z yang melalui Y. Analisis korelasi dan regresi yang merupakan dasar dari perhitungan koefisien jalur. Pengujian Hipotesis dalam penelitian ini menggunakan uji F. Uji F digunakan untuk menguji basarnya pengaruh variabel bebas stressor terhadap variabel terikat stress kerja dan prestasi kerja karyawan.

\section{HASIL PENELITIAN DAN PEMBAHASAN}

Gambaran karakteristik responden dapat diketahui berdasarkan hasil penyebaran kuesioner yang telah dilakukan kepada 40 responden yaitu karyawan bagian pemetik kopi pada PTPN XII (Persero) Kebun Ngrangkah Pawon Kediri. Maka dapat dikelompokkan berdasarkan usia, jenis kelamin, pendidikan terakhir, lama bekerja dan status perkawinan. Jenis kelamin karyawan PTPN XII (Persero) Kebun Ngrangkah Pawon Kediri dapat dilihat pada tabel berikut: 
58 Jurnal Manajemen Bisnis • Volume 3 No. 01 • Edisi April 2013

Tabel 2. Karakteristik Responden Berdasarkan Jenis Kelamin

\begin{tabular}{lcc}
\hline Jenis Kelamin & $\begin{array}{c}\text { Jumlah } \\
\text { Responden }\end{array}$ & Prosentase \\
\hline Laki-laki & 16 & $40 \%$ \\
Perempuan & 24 & $60 \%$ \\
Jumlah & 40 & $100 \%$ \\
\hline
\end{tabular}

Sumber: Data diolah

Dari Tabel 2 dapat diketahui bahwa dari 40 responden yaitu para pada PTPN XII (Persero) Kebun Ngrangkah Pawon Kediri menunjukkan bahwa sebanyak 16 responden atau sebesar $40 \%$ adalah laki-laki dan 24 responden atau $60 \%$ adalah perempuan. Berdasarkan hasil tersebut dapat membuktikan bahwa sebagain besar pegawai adalah perempuan.

Tabel 3. Karakteristik Responden Berdasarkan Usia

\begin{tabular}{ccc}
\hline Usia & $\begin{array}{c}\text { Jumlah } \\
\text { Responden }\end{array}$ & Prosentase \\
\hline $18-23$ tahun & 2 & $5 \%$ \\
$24-29$ tahun & 2 & $5 \%$ \\
$30-35$ tahun & 10 & $25 \%$ \\
$36-41$ tahun & 13 & $32,5 \%$ \\
$42-47$ tahun & 8 & $20 \%$ \\
$>48$ tahun & 5 & $12,5 \%$ \\
Jumlah & 40 & $100 \%$ \\
\hline
\end{tabular}

Sumber: Data diolah

Berdasarkan Tabel 3 dapat diketahui bahwa dari 40 responden yaitu para karyawan bagian pemetik pada PTPN XII (Persero) Kebun Ngrangkah Pawon Kediri menunjukkan bahwa sebanyak 13 responden atau $32,5 \%$ berusia $36-$ 41 tahun. Berdasarkan hasil tersebut dapat membuktikan bahwa selama ini PTPN XII (Persero) Kebun Ngrangkah Pawon Kediri banyak mempekerjakan karyawan yang berusia 36-41 tahun. Dari hasil tersebut dapat diketahui bahwa perusahaan mempekerjakan karyawan yang memiliki usia dalam kategori produktif dengan harapan para karyawan dapat bekerja secara maksimal di dalam perusahaan.
Tabel 4. Karakteristik Responden Berdasarkan Pendidikan Terakhir

\begin{tabular}{lcc}
\hline Pendidikan & $\begin{array}{c}\text { Jumlah } \\
\text { Responden }\end{array}$ & Prosentase \\
\hline SD & - & - \\
SMP & 12 & $30 \%$ \\
SMA & 28 & $70 \%$ \\
Diploma & - & - \\
Sarjana & - & - \\
$\quad$ Jumlah & 40 & $100 \%$ \\
\hline
\end{tabular}

Sumber: Data diolah

Berdasarkan Tabel 4 dari 40 responden yaitu para karyawan PTPN XII (Persero) Kebun Ngrangkah Pawon Kediri dapat diketahui bahwa sebanyak 28 responden atau 70\% mempunyai tingkat pendidikan Sekolah Menengah Atas. Hasil tersebut dapat membuktikan bahwa selama ini pihak perusahaan mempertimbangkan tingkat pendidikan formal dalam bakerja di perusahaan, karena hal tersebut dapat mempengaruhi tanggung jawab karyawan dalam penyelesaian pekerjaan yang telah dibebankan.

Tabel 5. Karakteristik Responden Berdasarkan Masa Kerja

\begin{tabular}{ccc}
\hline \multicolumn{1}{c}{ Lama Bekerja } & $\begin{array}{c}\text { Jumlah } \\
\text { Responden }\end{array}$ & Prosentase \\
\hline$<$ dari 1 tahun & 3 & $7,5 \%$ \\
1 tahun -5 tahun & 5 & $12,5 \%$ \\
6 tahun -10 tahun & 16 & $40 \%$ \\
11 tahun -15 tahun & 9 & $22,5 \%$ \\
$>$ dari 15 tahun & 7 & $17,5 \%$ \\
Jumlah & 40 & $100 \%$ \\
\hline
\end{tabular}

Sumber: Data diolah

Berdasarkan Tabel 5 dari 40 responden para karyawan PTPN XII (Persero) Kebun Ngrangkah Pawon Kediri menunjukkan bahwa sebanyak 16 responden atau $40 \%$. Berdasarkan hasil tersebut maka dapat disimpulkan bahwa sebagian besar karyawan telah bekerja pada perusahaan yaitu selama 6 tahun sampai 10 tahun. Masa kerja para responden tersebut dihitung mulai sejak awal masuk ke PTPN XII (Persero) Kebun Ngrangkah Pawon Kediri sampai sekarang. 
Tabel 6. Karakteristik Responden Berdasarkan Status Pernikahan

\begin{tabular}{lcc}
\hline $\begin{array}{c}\text { Status } \\
\text { Pernikahan }\end{array}$ & $\begin{array}{c}\text { Jumlah } \\
\text { Responden }\end{array}$ & Prosentase \\
\hline Menikah & 29 & $72,5 \%$ \\
Belum Menikah & 11 & $27,5 \%$ \\
Jumlah & 40 & $100 \%$ \\
\hline
\end{tabular}

Sumber: Data diolah

Berdasarkan Tabel 6 dari 40 responden yaitu para karyawan PTPN XII (Persero) Kebun
Ngrangkah Pawon Kediri menunjukkan bahwa sebanyak 29 responden atau sebesar 72,5\% sudah menikah. Hasil tersebut menunjukkan bahwa sebagian besar para karyawan PTPN XII (Persero) Kebun Ngrangkah Pawon Kediri adalah sudah menikah dan memiliki tanggungan keluarga sehingga tingkat kebutuhannya menjadi lebih tinggi.

Stressor adalah suatu kondisi yang cenderung menyebabkan stress. Berdasarkan hasil penelitian yang telah dilakukan maka analisis rentang skala variabel stressor dapat disajikan pada tabel berikut:

Tabel 7. Variabel Stressor (X)

\begin{tabular}{|c|c|c|c|c|c|c|c|}
\hline \multirow{2}{*}{ Item } & \multicolumn{5}{|c|}{ Frekuensi Jawaban Responden } & \multirow{2}{*}{$\begin{array}{l}\text { Skor Total } \\
\text { Indikator }\end{array}$} & \multirow{2}{*}{ Penilaian } \\
\hline & & A & $\mathbf{B}$ & $\mathbf{C}$ & D & & \\
\hline $\mathrm{X}_{1.1}$ & & 6 & 25 & 9 & - & 117 & Tinggi \\
\hline $\mathrm{X}_{1.2}$ & & 8 & 19 & 13 & - & 115 & Tinggi \\
\hline $\mathrm{X}_{1.3}$ & & 7 & 22 & 11 & - & 116 & Tinggi \\
\hline $\mathrm{X}_{1.4}$ & & 5 & 29 & 6 & - & 119 & Tinggi \\
\hline $\mathrm{X}_{1.5}$ & 8 & & 23 & 9 & - & 119 & Tinggi \\
\hline \multirow{2}{*}{\multicolumn{6}{|c|}{$\begin{array}{c}\text { Total Skor Variabel } \\
\text { Rata-Rata Skor Variabel }\end{array}$}} & 586 & - \\
\hline & & & & & & 117,2 & Tinggi \\
\hline
\end{tabular}

Sumber: Data diolah

Berdasarkan hasil perhitungan rata-rata rentang skala diperoleh angka sebesar 117,2 yang berarti bahwa stressor yang terjadi pada PTPN XII (Persero) Kebun Ngrangkah Pawon Kediri masuk dalam kategori tinggi. Hal tersebut dapat dibuktikan dari beberapa karyawan yang merasa tuntutan pekerjaan yang diberikan terlalu berlebihan. Karyawan juga merasa kepribadian karyawan mudah tertekan, dan adanya tekanan dari karyawan lain. Aturan dan pengaturan yang diterapkan perusa- haan dirasa juga telalu berlebihan, dan karyawan merasa gaya kepemimpinan atasan dalam pengambilan keputusan hanya secara sepihak.

Stress kerja adalah suatu tanggapan penyesuaian yang diperantarai oleh perbedaan individu dan atau proses psikologis yang merupakan suatu konsekuensi dari suatu lingkungan. Berdasarkan hasil penelitian yang telah dilakukan maka analisis rentang skala variabel stress kerja dapat disajikan pada tabel berikut:

Tabel 8. Variabel Stress Kerja (Y)

\begin{tabular}{ccccccc}
\hline Item & A & $\begin{array}{c}\text { Frekuensi Jawaban Responden } \\
\text { B }\end{array}$ & C & D & $\begin{array}{c}\text { Skor Total } \\
\text { Indikator }\end{array}$ & Penilaian \\
\hline $\mathrm{Y}_{1.1}$ & 8 & 12 & 9 & 8 & 111 & Tinggi \\
$\mathrm{Y}_{1.2}$ & 18 & 15 & 16 & 23 & 115 & Tinggi \\
$\mathrm{Y}_{1.3}$ & 11 & 9 & 12 & 6 & 111 & Tinggi \\
$\mathrm{Y}_{1.4}$ & 3 & 4 & 3 & 3 & 116 & Tinggi \\
& \multicolumn{2}{c}{ Total Skor Variabel } & & 453 & - \\
& Rata-Rata Skor Variabel & & 113,25 & Tinggi \\
\hline
\end{tabular}


Berdasarkan hasil perhitungan rata-rata rentang skala diperoleh angka sebesar 113,25 yang berarti bahwa stress kerja yang terjadi pada PTPN XII (Persero) Kebun Ngrangkah Pawon Kediri masuk dalam kategori tinggi. Hal tersebut dapat membuktikan bahwa karyawan merasa cepat bosan pada saat bekerja. Karyawan juga mudah marah atau tersinggung pada saat bekerja dan berinteraksi dengan karyawan lain. Selain itu karyawan juga sering mengalami gangguan fisik seperti mual, pusing, otot kejang pada saat bekerja.
Prestasi kerja karyawan adalah suatu hasil karya yang dicapai seseorang dalam melaksanakan tugas-tugas yang dibebankan kepadanya, yang didasarkan atas kecakapan, pengalaman dan kelangsungan waktu serta ukuran yang telah ditetapkan oleh perusahaan yang pada gilirannya akan menentukan keseluruhan dari keberhasilan. Berdasarkan hasil penelitian yang telah dilakukan maka analisis rentang skala variabel kinerja karyawan dapat disajikan pada tabel berikut:

Tabel 9. Variabel Prestasi Kerja (Z)

\begin{tabular}{ccccccc}
\hline Item & \multicolumn{2}{c}{ Frekuensi Jawaban Responden } & Skor Total & \multirow{2}{*}{ Penilaian } \\
& A & B & C & D & Indikator & Tinggi \\
$\mathrm{Z}_{1.1}$ & 11 & 8 & 12 & 21 & 122 & Tinggi \\
$\mathrm{Z}_{1.2}$ & 19 & 11 & 7 & 9 & 111 & Tinggi \\
$\mathrm{Z}_{1.3}$ & 15 & 1 & 4 & 2 & 113 & - \\
& \multicolumn{7}{c}{ Total Skor Variabel } & & 346 & Tinggi \\
\hline
\end{tabular}

Sumber: Data diolah

Berdasarkan hasil perhitungan rata-rata rentang skala diperoleh angka sebesar 115,3 yang berarti bahwa prestasi kerja kerja yang terjadi pada PTPN XII (Persero) Kebun Ngrangkah Pawon Kediri masuk dalam kategori tinggi. Hal tersebut dapat membuktikan bahwa karyawan merasa cepat bosan pada saat bekerja. Karyawan juga mudah marah atau tersinggung pada saat bekerja dan berinteraksi dengan karyawan lain. Selain itu karyawan juga sering mengalami gangguan fisik seperti mual, pusing, otot kejang pada saat bekerja.

Untuk mengetahui hasil analisis jalur (path analisys) yang telah dilakukan maka secara lengkap dapat dilihat pada tabel 10 berikut:

Tabel 10 Pengaruh stressor $(\mathrm{X})$ terhadap prestasi kerja(Z) Melalui stress kerja(Y)

\begin{tabular}{ccccc}
\hline Variabel & Koefisien Regresi & Standar Error & $\mathbf{t}_{\text {hitung }}$ & Sig. \\
\hline $\mathrm{X}$ & 0,096 & 0,115 & 4.492 & 0,000 \\
Y & 0,427 & 0,095 & &
\end{tabular}

Koefisien Determinasi $\left(\mathrm{R}^{2}\right): 0,608$

Koefisien Korelasi (R): 0,780

Sumber: Data diolah

Berdasarkan Tabel 10 maka dapat diuraikan hasil analisis regresi mengenai pengaruh stressor terhadap stress kerja, pengaruh stress kerja terhadap prestasi kerja, dan pengaruh stressor terhadap prestasi kerja melalui stress kerja pada karyawan PTPN XII (Persero) Kebun Ngrangkah
Pawon Kediri. Sedangkan Nilai $\mathrm{F}_{\text {hitung }}$ sebesar 28,685 sedangkan nilai $F_{\text {tabel }}$ yaitu sebesar 4,08. Berdasarkan hasil tersebut maka dapat disimpulkan bahwa stressor yang meliputi tuntutan tugas, tuntutan peran, tuntutan antar pribadi, struktur organisasi, dan kepemimpinan organisasi secara ber- 
sama-sama mempunyai pengaruh yang signifikan terhadap terhadap prestasi kerja yang melalui stress kerja karyawan pada PTPN XII (Persero) Kebun Ngrangkah Pawon Kediri.

\section{SIMPULAN}

Simpulan yang dapat diambil dari penelitian ini adalah pertama: stressor kerja karyawan pada PTPN XII (Persero) Kebun Ngrangkah Pawon Kediri masuk dalam kategori tinggi. Kedua: stress kerja karyawan pada PTPN XII (Persero) Kebun Ngrangkah Pawon Kediri masuk dalam kategori tinggi. Ketiga: prestasi kerja karyawan pada PTPN XII (Persero) Kebun Ngrangkah Pawon Kediri masuk dalam kategori tinggi. Keempat: terdapat pengaruh yang signifikan antara stressor terhadap stress kerja karyawan pada PTPN XII (Persero) Kebun Ngrangkah Pawon Kediri. Kelima: terdapat pengaruh yang signifikan antara stress kerja terhadap prestasi kerja karyawan pada PTPN XII (Persero) Kebun Ngrangkah Pawon Kediri. Keenam: terdapat pengaruh yang signifikan antara stressor terhadap prestasi kerja yang melalui stress kerja karyawan pada PTPN XII (Persero) Kebun Ngrangkah Pawon Kediri.

\section{DAFTAR PUSTAKA}

Arikunto, Suharsimi. 2002. Prosedur Penelitian Suatu Pendekatan Praktek. EdisiRevisi V. Penerbit Rineka Cipta: Jakarta.
Darma, Agus. 1991. Manajemen Prestasi Kerja. Edisi Ketiga. Penerbit Erlangga: Jakarta.

Gibson, Ivancevich, Donnelly. 1996. Organisasi. Jilid Pertama. Penerbit Binarupa Aksara: Jakarta.

Handoko, Hani. 1993. Manajemen Personalia Sumber Daya Manusia. Edisi Pertama. Penerbit BPFE: Yogyakarta.

Mangkunegara, Anwar Prabu. 2000. Manajemen Sumber Daya Manusia Perusahaan. Cetakan Kedua, PT. Remaja Rosdakarya Offset: Bandung.

Rivanto, Jerry. 2009. Jurnal Pengaruh Stressor Terhadap Stress Kerja Dan Kinerja Karyawan Pada Perusahaan Susu Sapi Anugerah Kediri. Fakultas Ekonomi Dan Bisnis Jurusan Manajemen Universitas Muhammadiyah Malang.

Robbins, Stephen. 1996. Perilaku Organisasi Konsep Kontoversi Aplikasi. Terjemahan Hadyana Pujaatmaka. Jilid 2. Prenhalindo: Jakarta.

Umar, Husein. 2004. Riset Sumber Daya Manusia dalam Organisasi. Gramedia Pustaka Utama: Jakarta.

Widayat dan Amrullah. 2002. Riset Bisnis. Edisi Pertama. Malang: CV. CahayaPress. 